\title{
Características biométricas e emergência de plântulas de Brosimum gaudichaudii Tréc. oriundas de diferentes procedências do cerrado mato-grossense
}

\author{
FARIA, R.A.P.G. ${ }^{1 *}$; SILVA, A.N. ${ }^{1}$; ALBUQUERQUE, M.C.F. ${ }^{1}$, COELHO, M.F.B. ${ }^{2}$ \\ Departamento de Fitotecnia e Fitossanidade, UFMT/FAMEV, Av. Fernando Correa da Costa s/n, CEP: 78060-900, \\ Cuiabá-Brasil *rozilaine@yahoo.com.br ${ }^{2}$ Departamento de Ciências Vegetais, Universidade Federal Rural do \\ Semi-Árido. Km 47 BR 110 Bairro Presidente Costa e Silva, CEP: 59625-900, Mossoró-Brasil.
}

\begin{abstract}
RESUMO: Brosimum gaudichaudii Tréc. (Moraceae), espécie típica do cerrado, popularmente conhecida como algodãozinho e mama-cadela, é muito apreciada pelo sabor adocicado dos frutos. É planta medicinal utilizada para o tratamento do vitiligo. O objetivo deste trabalho foi avaliar as características biométricas das sementes, a emergência e o desenvolvimento de plântulas provenientes de diferentes locais do cerrado mato-grossense. A coleta das sementes foi realizada aleatoriamente e o delineamento foi inteiramente casualizado com três tratamentos (procedência das sementes) e quatro repetições. As características biométricas das sementes, de cada procedência, foram medidas com paquímetro digital. As sementes foram distribuídas em substrato de areia, em caixas de plástico, a profundidade de $2 \mathrm{~cm}$ e colocadas a $26^{\circ} \mathrm{C}$ e $40 \%$ de umidade relativa por 42 dias. Foram consideradas como germinadas as sementes que formaram plântulas com $2 \mathrm{~cm}$ de altura. As variáveis observadas foram: dimensão das sementes, massa de 100 sementes, porcentagem e tempo médio de emergência de plântulas, altura, diâmetro basal e número de folhas das plântulas e o nível de coloração do caule (verde, róseo, avermelhado e vermelho). Apesar de não ter havido diferença na porcentagem de emergência de plântulas de Brosimum gaudichaudiidas três procedências foram verificadas diferenças significativas tanto para o tempo médio de emergência quanto para o desenvolvimento de plântulas de diferentes procedências.
\end{abstract}

Palavras-chave: Moraceae, germinação, biometria, plantas medicinais, cerrado

\begin{abstract}
Biometric characteristics and emergence of Brosimum gaudichaudii Tréc. seedlings from different parts of "Cerrado mato-grossense". Brosimum gaudichaudii Tréc. (Moraceae), a typical Cerrado species popularly known as "algodãozinho" and "mama-cadela", is greatly appreciated for the sweet flav or of its fruits. It is a medicinal plant used to treat vitiligo. The aim of this work was to evaluate the biometric characteristics of seeds and the emergence and development of seedlings from different parts of "cerrado mato-grossense". Seeds were randomly collected and the experimental design was completely randomized with three treatments (seed provenances) and four replicates. Seed biometric characteristics were measured with a digital pachymeter. The seeds were distributed into sand substrate in plastic boxes at $2 \mathrm{~cm}$ depth and stored at $26^{\circ} \mathrm{C}$ and $40 \%$ relative humidity for 42 days. Seeds were considered germinated when they formed $2 \mathrm{~cm}$-tall seedlings. The following characteristics were analyzed: seed dimensions, 100-seed weight, seedling emergence percentage and mean time, height, basal diameter, leaf number and stem color degree (green, pinkish, reddish and red). Although there was no difference in the emergence percentage of Brosimum gaudichaudiffom the three provenances, significant differences were verified for both emergence mean time and development of seedlings from distinct provenances.
\end{abstract}

Key words: Moraceae, germination, biometry, medicinal plants, cerrado

\section{INTRODUÇÃO}

A flora do Cerrado é bem característica, diferenciando-se da vegetação de biomas vizinhos. $A$ distribuição dessa vegetação está condicionada a diversos fatores tais como nível do lençol freático, freqüência de queimadas, pastejo, ação antrópica e extrativismo vegetal (Ratter \& Ribeiro, 1996; Ribeiro

Recebido para publicação em 17/10/2008

Aceito para publicação em 04/07/2009

Rev. Bras. PI. Med., Botucatu, v.11, n.4, p.414-421, 2009. 
\& Walter, 1998).

Segundo Fernandez (2002), estudos sobre a conservação e propagação de espécies nativas contribuem para minimizar a perda da biodiversidade. São muitas as espécies medicinais consagradas que possuem técnicas de cultivo e beneficiamento bem definidas, principalmente no exterior, mas no Brasil as informações quanto aos aspectos agronômicos são ainda restritas (Scheffer et al., 1999).

Na região do Cerrado, Brosimum gaudichaudii Tréc. é árvore amplamente utilizada na medicina popular, no tratamento do vitiligo e como depurativo do sangue (Pereira et al., 2006). É conhecida em Mato Grosso como algodãozinho, marjejum, ou mama-cadela. Essa espécie típica do cerrado está sob ameaça de extinção por estar inserida em ambiente em constante mudança, seja por queimadas espontâneas, seja pela constante expansão da fronteira agrícola. Dessa forma, destaca-se a necessidade de se conhecer as características da espécie para possibilitar subsídios para a produção de mudas com o conseqüente repovoamento dos locais devastados.

Apesar de pouco estudada, a procedência das sementes parece desempenhar influência sobre a germinação e emergência de plântulas. Além da temperatura, outros fatores como clima e composição de solo seriam importantes na determinação do desempenho das sementes bem como da sua qualidade (Carvalho \& Nakagawa, 2000). Essa qualidade pode ser avaliada por diferentes características, sejam físicas (teor de água, massa de 1000 sementes, massa de material seco) sejam fisiológicas (porcentagem e velocidade de germinação, viabilidade e vigor) (Leonhardt et al., 2001).

Apesar da procedência poder influenciar na porcentagem de germinação, Alves et al. (2005) verificaram que o vigor de mudas de Mimosa caesalpiniifolia Benth foi condicionado pelo tamanho das sementes. Entretanto, a relação tamanho versus porcentagem de germinação não se aplica genericamente a todas as espécies, assim como tamanho com vigor. A relação entre tamanho da semente e a sobrevivência da muda em condições limites apresenta muita controvérsia, principalmente no que se refere a necessidade de nutrientes pela plântula. A massa da semente não é um fator para prever a qualidade fisiológica da muda, pois o estabelecimento da plântula em campo envolve, além das reservas adquiridas após a germinação, a interação da plântula com o meio ao qual será inserida (Hanley et al., 2007).

Espécies que produzem sementes grandes estariam mais predispostas a suportar situações de estresse. As vantagens das sementes grandes sobre as demais é que são facilmente encontradas em ambientes sombreados e estão adaptadas a ambientes predispostos a estresse hídrico. Sementes pequenas têm a dispersão mais favorecida enquanto que, nas sementes grandes, as mudas seriam mais facilmente estabelecidas, haja vista apresentar maior quantidade de nutrientes e conter mais reserva de energia (Malavasi \& Malavasi, 2001).

Sementes grandes produzem mudas mais vigorosas, porém sementes pequenas apresentam maior porcentagem de germinação, além de germinarem mais rápido e serem mais persistentes em bancos de sementes no solo, facilitando a penetração em pequenas dimensões, além da produção em maior quantidade aumentar as chances de uma parcela escapar de predadores (Malavasi \& Malavasi, 2001). Esses autores concluíram que a germinabilidade não está condicionada ao tamanho da semente, mas sim aos fatores externos como o ambiente em que se encontra.

Assim, a relação do tamanho com a sobrevivência estaria relacionada com os microhabitats bem como com a interação entre eles, estimulando ou inibindo os processos de crescimento. No entanto, a classificação das sementes por tamanho ou peso pode servir como estratégia para uniformizar a germinação, bem como, a obtenção de mudas de tamanho e vigor semelhantes. Porém, a manutenção da plântula no meio tem maior correlação com a qualidade fisiológica da muda (Martins et al., 2000; Ferreira \& Torres, 2000; Rey et al., 2004). No entanto, Botezelli et al. (2000) sugeriram que outras variáveis como pluviosidade, temperatura, comprimento do dia e tipo de solo podem influenciar o desempenho da semente por ressaltar aspectos condicionados a composição genética possibilitadas pelas variantes ambientais adequadas.

Este trabalho teve como objetivo avaliar o efeito da procedência sobre as características biométricas das sementes e a emergência e desenvolvimento de plântulas.

\section{MATERIAL E MÉTODO}

As sementes de Brosimum gaudichaudii Tréc foram obtidas de frutos maduros coletados entre setembro e outubro de 2007, em três diferentes localidades do Estado do Mato Grosso (MT) chamadas de procedências: Cabeceira do Rio Cuiabá (P1), com coordenadas $14^{\circ} 27^{\prime} 31.9^{\prime \prime}$ S e $55^{\circ} 14^{\prime} 03.0^{\prime \prime}$ W; na comunidade de Mata Cavalo (P2) em Nossa Senhora do Livramento-MT, com coordenadas $15^{\circ} 50^{\prime}$ 34.9" S e 56 24' 03.0" W e em Cuiabá-MT (P3), no bairro Bela Vista, com coordenadas $15^{\circ} 34^{\prime} 41,7^{\prime \prime} \mathrm{Se}$ $56^{\circ} 03^{\prime} 35,2^{\prime \prime}$ W. Os indivíduos foram devidamente identificados pela curadoria do Herbário Central da UFMT.

Os frutos foram lavados em água corrente e a polpa retirada manualmente em peneira $4 \mathrm{~mm}$ para a obtenção das sementes, no Laboratório de Análise 
de Sementes da Faculdade de Agronomia e Medicina Veterinária da Universidade Federal de Mato Grosso.

Após o processamento, foi determinado o teor de água das sementes pelo método de estufa de circulação gravitacional a $10^{\circ} \mathrm{C} \pm 3^{\circ} \mathrm{C}$ por 24 horas e a massa de mil sementes (Brasil, 1992). Foram determinadas também as características biométricas das sementes oriundas das três procedências: comprimento, largura e espessura, com uso de paquímetro digital, todas com oito repetições de 10 sementes.

Para o teste de emergência de plântulas, as sementes foram homogeneizadas, desinfectadas com hipoclorito de sódio a $5 \%$ e retirado o tegumento na região do hilo. Em seguida, foram distribuídas em substrato de areia a profundidade de $2 \mathrm{~cm}$, em caixas plásticas, com o eixo embrionário na horizontal. A areia foi previamente esterilizada e umedecida com água a $60 \%$ da capacidade de campo, em volume. As bandejas ficaram cobertas com sacolas plásticas transparentes para manter a umidade da areia e colocadas em ambiente a $26 \% \mathrm{C}$ e $40 \%$ sob fotoperíodo de 8 horas. Foram consideradas como germinadas as sementes que formaram plântulas com $2 \mathrm{~cm}$ de altura. Após a emergência das plântulas, as sacolas foram retiradas e o substrato umedecido quando necessário. O delineamento foi inteiramente casualizado com três procedências e quatro repetições.

No final do período, aos 42 dias após a semeadura, foram calculados a porcentagem, 0 tempo médio e a freqüência relativa de emergência de plântulas em função do tempo de semeadura (Laboriau \& Valadares, 1976). Também foram medidos a altura e o diâmetro basal com paquímetro digital e contado o número de folhas. A avaliação da coloração do caule das plântulas emergidas foi realizada visualmente e classificada em quatro níveis, verde, róseo, avermelhado e vermelho.

Os resultados foram submetidos à análise de variância e os dados que não apresentaram distribuição normal e homocedasticidade transformados em arco seno (raiz x/100). Na comparação das médias utilizou-se o teste de Tukey a $5 \%$. Para as análises estatísticas foi utilizado o software SAEG Sistema de análises estatísticas e genéticas da Universidade Federal de Viçosa-MG.

\section{RESULTADO E DISCUSSÃO}

Os frutos de Brosimum gaudichaudii são do tipo drupa, reunidos em infrutescência globosa, amarelo-alaranjada quando madura. A superfície é verrucosa com polpa carnosa, sabor adocicado e comestível enquanto que as sementes são de coloração creme. Em todos os frutos despolpados havia apenas uma semente, embora Almeida et al. (1998), Lorenzi (2002) e Lorenzi et al. (2002) citem a presença de 1 ou 2 sementes por fruto.

O teor de água das sementes (base úmida) encontrava-se alto e variou de 40,7\% a 41,5\% (Tabela 1). A massa de 1000 sementes da $P 1$ foi maior que as oriundas das demais procedências, enquanto que a maior variância ocorreu entre as sementes provenientes de P2, indicando que esse material é mais heterogêneo enquanto que o mais homogêneo foi da origem P3. Entre as procedências P1 e P3 não ocorreram variações na massa de mil sementes.

Os frutos coletados na cabeceira do rio Cuiabá (P1) apresentavam coloração amareloalaranjado e eram maiores e mais homogêneos (Tabela 1). Já os de Mata Cavalo (P2) eram pequenos e médios, conforme critério de classificação por classes, apresentando maior heterogeneidade, e os frutos de Cuiabá (P3) foram classificados como de tamanho médio. O comprimento, a largura e a espessura das sementes de P1 foram maiores que as das demais procedências, enquanto que entre P2 e P3 não ocorreram diferenças. Os dados biométricos apresentaram não significância para o teste de Lilliefors (normalidade). No entanto, pela alta significância apresentada pelo teste $\mathrm{F}$ da Anova, somente o fato de haver homocedasticidade é suficiente para desconsiderar-se a condição de não normalidade (Sokal \& Rohlf, 1997). A espessura de sementes de $B$. gaudichaudii foi estatisticamente diferente entre as três procedências (Tabela 1). Ferreira

TABELA 1. Características físicas de sementes de Brosimum gaudichaudii das procedências Cabeceira (P1), Mata Cavalo (P2) e Cuiabá (P3).

\begin{tabular}{lccc}
\hline \multicolumn{1}{c}{ Característica/Procedência } & $\mathrm{P} 1$ & $\mathrm{P} 2$ & $\mathrm{P} 3$ \\
\hline Teor de água $(\%)$ & 40,7 & 40,3 & 41,5 \\
Massa de mil sementes $(\mathrm{g})$ & $27,04 \pm 0,80 \mathrm{a}$ & $14,76 \pm 1,39 \mathrm{~b}$ & $14,62 \pm 0,70 \mathrm{~b}$ \\
Variância de massa $\left(\sigma^{2}\right)$ & 0,64 & 1,94 & 0,49 \\
Comprimento $(\mathrm{mm})$ & $19,47 \pm 0,29 \mathrm{a}$ & $15,82 \pm 0,55 \mathrm{~b}$ & $16,21 \pm 0,42 \mathrm{~b}$ \\
Largura $(\mathrm{mm})$ & $16,65 \pm 0,23 \mathrm{a}$ & $13,36 \pm 0,39 \mathrm{~b}$ & $13,07 \pm 0,27 \mathrm{~b}$ \\
Espessura $(\mathrm{mm})$ & $12,08 \pm 0,15 \mathrm{a}$ & $10,98 \pm 0,21 \mathrm{~b}$ & $9,64 \pm 0,13 \mathrm{c}$ \\
\hline
\end{tabular}

média \pm desvio padrão; médias seguidas de mesma letra, na linha, não diferem estatisticamente pelo teste Tukey a $5 \%$. 
\& Torres (2000) não verificaram diferenças significativas na espessura de sementes de diferentes tamanhos de Acacia Senegal (L.) de Willd, enquanto que para sementes de Mimosa caesalpiniifolia Benth foi observada diferença na espessura das sementes de tamanhos diferentes (Alves et al., 2005).

Os valores das medidas de comprimento, largura e espessura foram distribuídos em classes de freqüência para verificar a freqüência relativa de cada variável biométrica. Assim, observa-se para as sementes $\mathrm{P} 1$ que $25 \%$ do comprimento estavam distribuídos entre 18,96 a $19,98 \mathrm{~mm} ; 28,75 \%$ da largura entre 15,93 a 16,79 e $28,75 \%$ e da espessura entre 11,59 e 12,20 mm (Figuras 1A, 1B e 1C).

Para $\mathrm{P} 2,32,5 \%$ do comprimento estavam entre 14,15 a $15,42 \mathrm{~mm} ; 18,75 \%$ da largura entre 12,91 a 13,78 e $23,75 \%$ da espessura entre 10,43 e 10,92 mm (Figuras 2A, 2B e 2C).

Para P3, 27,5\% do comprimento entre 15,38 e $16,12 \mathrm{~mm} ; 27,5 \%$ da largura entre 12,60 e 13,26 $\mathrm{mm}$ e $27,5 \%$ da espessura entre 9,19 e $9,51 \mathrm{~mm}$ (Figuras 3A, 3B e 3C).

Ainda, os polígonos formados (Figuras $1 \mathrm{Ae}$ 1C) apresentam simetria, indicativo de lote homogêneo enquanto que para os demais os dados estão distribuídos assimetricamente indicando heterogeneidade do lote.

A porcentagem de emergência de plântulas não foi diferente entre as sementes das três procedências (Tabela 2) enquanto que para o tempo médio de emergência foram verificadas variações significativas. As sementes oriundas de P3 apresentaram a maior velocidade, com tempo médio de 19,4 dias. Essas sementes apresentaram menor espessura, mas em comprimento e largura foram iguais às sementes oriundas de P2. Conforme Popinigis (1985), para muitas espécies, sementes pequenas dentro de um mesmo lote apresentam menor germinação e vigor do que as médias e grandes; Krzyzanowski et al. (1999) afirmaram que sementes de menor tamanho germinam com maior velocidade por necessitarem de menor quantidade água para embebição. Também outras variáveis como pluviosidade, temperatura, comprimento do dia e tipo de solo podem influenciar o desempenho da semente por ressaltar aspectos condicionados a composição genética possibilitadas pelas variantes ambientais adequadas (Botezelli et al., 2000).

A influência do tamanho das sementes na germinação é controversa. Em Euterpe espiritosantensis Fernandes as sementes de maior tamanho apresentaram maiores porcentagem e velocidade de germinação quando comparadas com as sementes menores (Martins et al., 2000). Por outro lado, o tamanho da semente não influenciou a porcentagem de germinação em sementes de cagaiteira (Eugenia dysenterica DC.), porém as sementes grandes tiveram maior índice de velocidade de germinação e desenvolveram mudas de melhor qualidade (Niestche et al., 2004). Em Acacia senega (L.) Willd. o tamanho das sementes não influenciou nem a velocidade nem a porcentagem de germinação (Ferreira \& Torres, 2000).
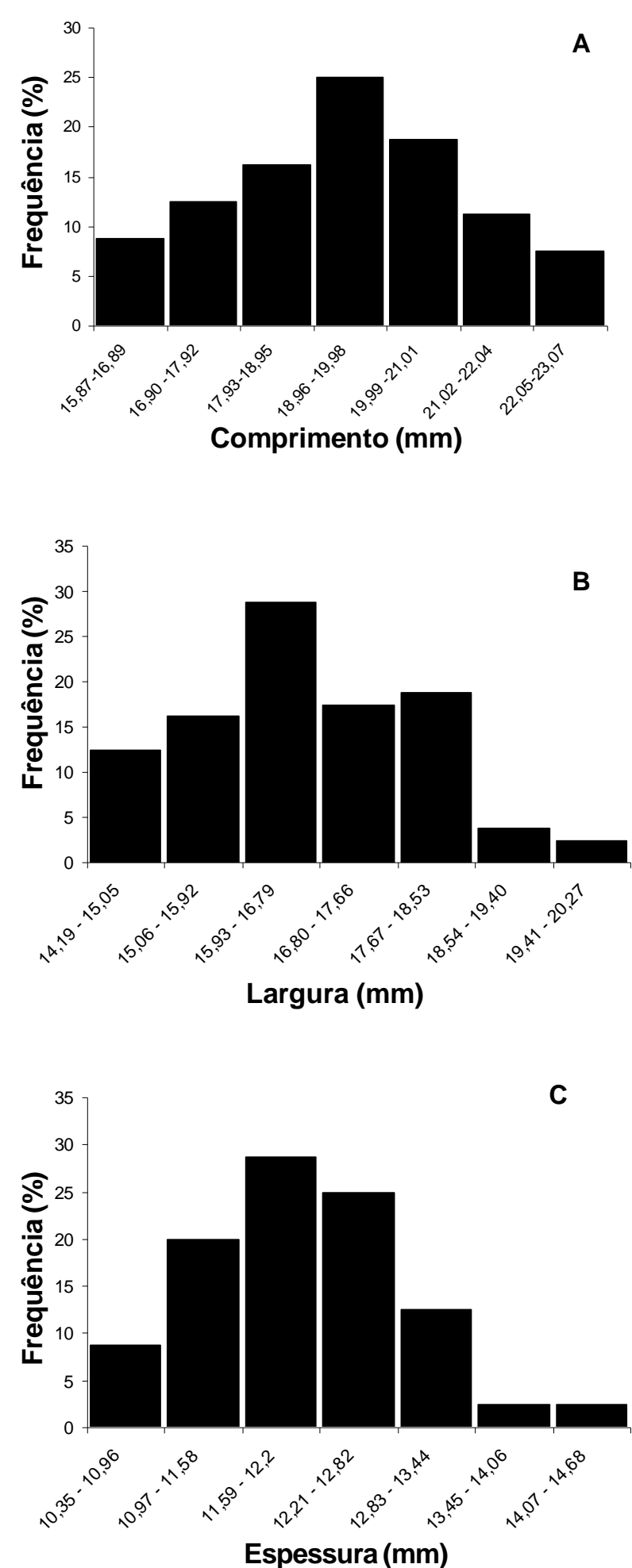

FIGURA 1. Classes das sementes provenientes da Cabeceira do Rio Cuiabá-MT (P1): comprimento (A), largura (B) e espessura (C). 

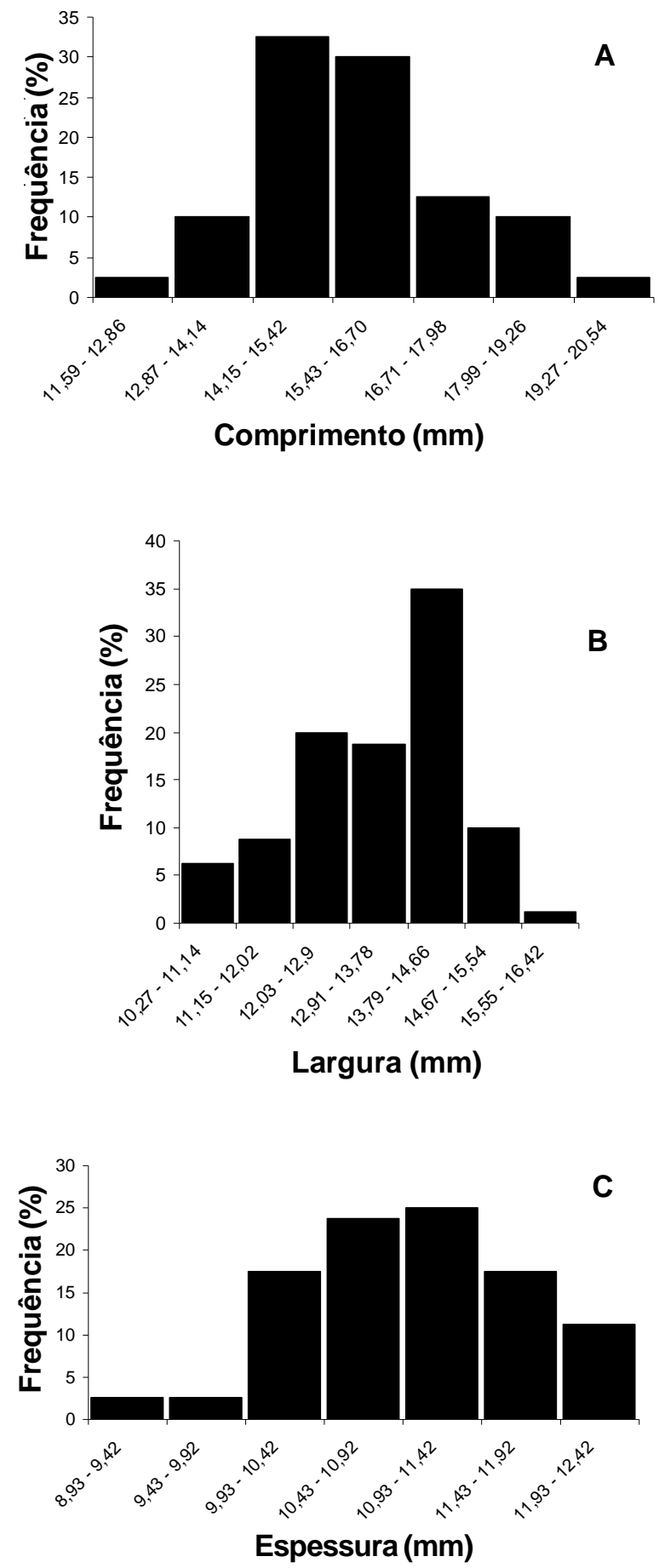

FIGURA 2. Classes de sementes provenientes de Mata Cavalo-MT (P2): comprimento (A), largura (B) e espessura (C).

Foram verificadas diferenças significativas entre as procedências para altura e diâmetro basal das plântulas. A maior altura foi verificada para $\mathrm{P} 3$ e 0 maior diâmetro basal para P1 (Tabela 3). Observase, pela Tabela 1, que P1 apresentou maior massa de sementes e maior tamanho. Silva et al. (1994) observaram que sementes de Eucalyptus maculata Hook de maior tamanho produziram plântulas de
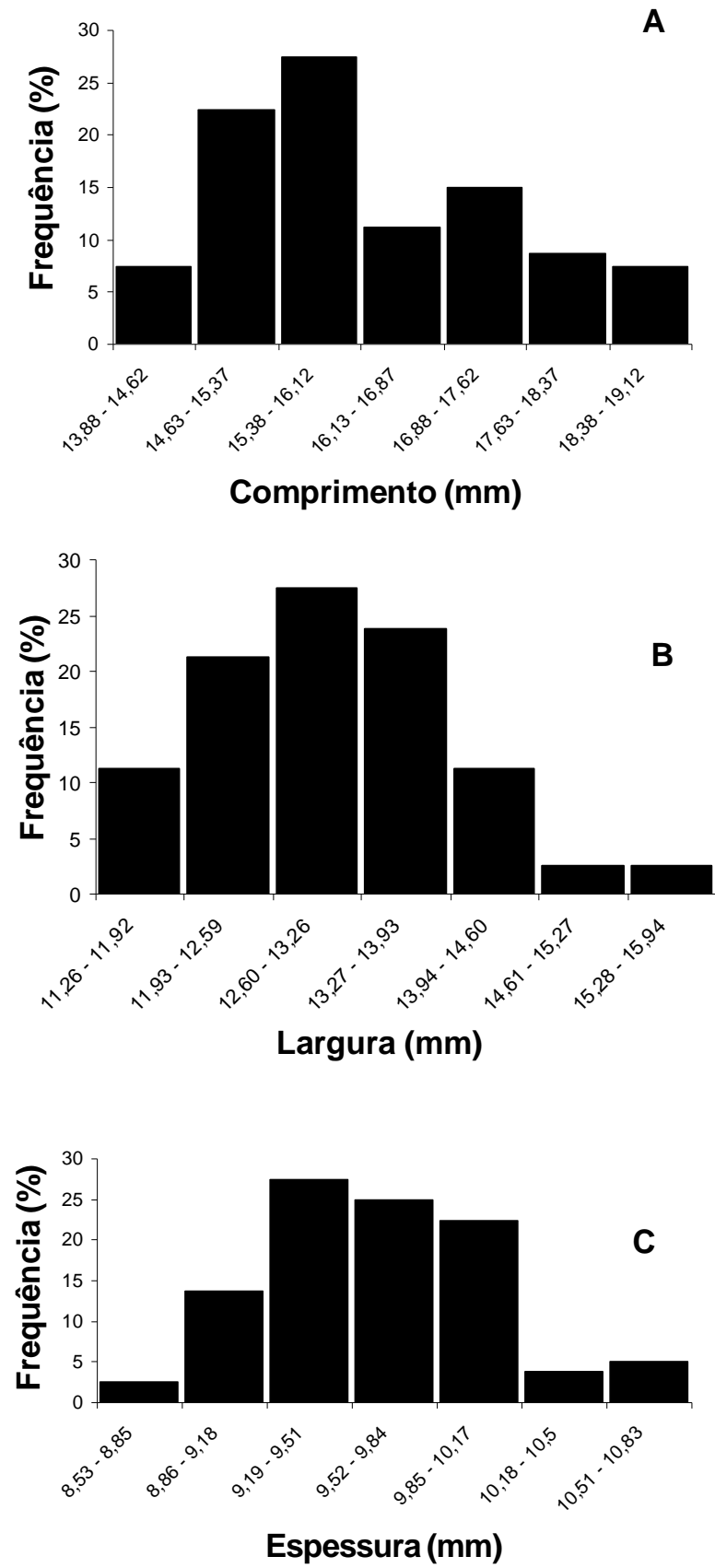

FIGURA 3. Classes de espessura das sementes provenientes de Cuiabá-MT (P3): comprimemnto (A), largura (B) e espessura (C).

maior altura, pois tiveram desenvolvimento inicial mais rápido em relação as sementes menores. O número de folhas não diferiu estatisticamente entre as procedências (Tabela 3 ), diferindo do verificado por Nietsche et al. (2004) que, em sementes de Eugenia dysenterica, observaram que as sementes maiores produziram plântulas com maior altura e maior número folhas. 
TABELA 2. Tempo médio e porcentagem de emergência de plântulas de $B$. gaudichaudiioriundas de diferentes procedências.

\begin{tabular}{cccc}
\hline $\begin{array}{c}\text { Variável observada/ } \\
\text { Procedência }\end{array}$ & P1 & P2 & P3 \\
\hline TM (dias) & $23,54 a$ & $23,78 a$ & $19,4 b$ \\
ME (\%) & $91 \mathrm{a}$ & $81 \mathrm{a}$ & $83 \mathrm{a}$ \\
\hline
\end{tabular}

TM: tempo médio; ME: média emergência; médias seguidas de mesma letra, na linha, não diferem estatisticamente a $5 \%$ pelo teste Tukey. ${ }^{1}$ Para a análise estatística, os dados foram transformados para arco seno (raiz x/100) mas na tabela encontram-se as médias originais.

TABELA3. Altura $(\mathrm{H})$, diâmetro basal (DB) e número de folhas (NF) de plântulas de $B$. gaudichaudii, aos 42 dias após a semeadura.

\begin{tabular}{cccc}
\hline Procedência & $\mathrm{H}(\mathrm{cm})$ & $\mathrm{DB}(\mathrm{mm})$ & $\mathrm{NF}$ \\
\hline 1 & $9,65 \mathrm{~b}$ & $1,64 \mathrm{a}$ & $3 \mathrm{a}$ \\
2 & $8,96 \mathrm{~b}$ & $1,36 \mathrm{~b}$ & $3 \mathrm{a}$ \\
3 & $14,10 \mathrm{a}$ & $1,28 \mathrm{~b}$ & $3 \mathrm{a}$ \\
\hline
\end{tabular}

Médias seguidas de mesma letra, na coluna, não diferem entre si pelo teste Tukey a $5 \%$.

Em Mimosa caesalpiniifolia Benth, o vigor da plântula esteve diretamente relacionado com o tamanho da semente, justificando a classificação por tamanho para a formação de mudas (Alves et al., 2005). No entanto, para Brosimum gaudichaudii as sementes maiores formaram plântulas de maior diâmetro basal e não de maior altura, ao se comparar sementes de mesma espécie, porém de diferentes

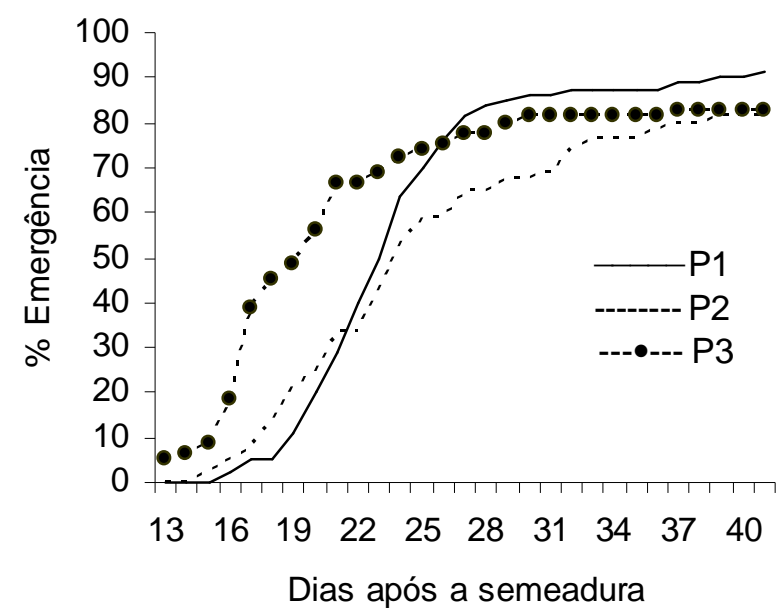

FIGURA 4. Porcentagem de emergência em função do período após a semeadura. final de 42 dias, as porcentagens de emergência das três procedências não apresentaram diferenças.

Nas Figuras 5, 6 e 7 verificam-se a formação de polígonos polimodais evidenciando germinação heterogênea, típica de plantas nativas, independentemente das procedências. O predomínio de polígonos polimodais evidencia heterogeneidade

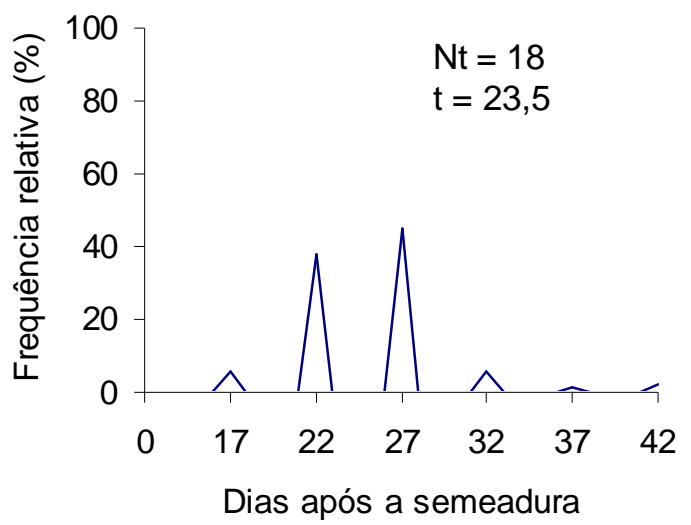

FIGURA 5. Freqüência relativa de germinação das sementes de $B$. gaudichaudii (P1). Nt: número de sementes t: tempo médio (dias)

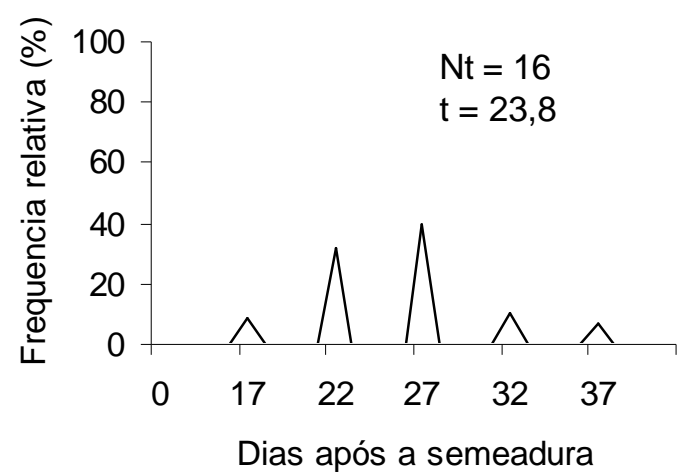

FIGURA 6. Freqüência relativa de germinação das sementes de B. gaudichaudii (P2). Nt: número de sementes t: tempo médio (dias)

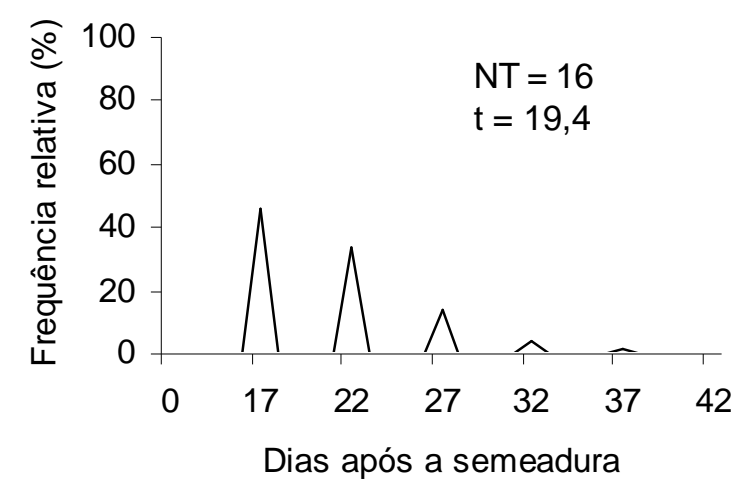

FIGURA 7. Freqüência relativa de germinação das sementes de B. gaudichaudii (P3). Nt: número de sementes t: tempo médio (dias) 
do lote em estudo, confirmando assim a natureza heterogênea da germinação das plantas nativas de cerrado (Borghetti \& Ferreira, 2004).

Pode-se observar que o tempo médio de germinação da procedência 3 (Figura 7), foi deslocado para a esquerda, sugerindo maior velocidade de germinação.

Aos 42 dias após a semeadura foi observado que a coloração do caule variou entre verde, avermelhado, róseo e vermelho. Essa separação de cores foi verificada em diferentes freqüências entre as procedências (Figura 8). Para P3, a maior proporção foi de coloração verde (42\%) enquanto que para P1 a maior proporção foi de vermelho (43\%). Para P2 houve maior heterogeneidade na coloração com $23 \%$ de plântulas com coloração de caule vermelho e $26 \%$ verde. Essa variabilidade de coloração de caule das plântulas pode estar relacionada com a variabilidade genética encontrada em plantas nativas, merecendo verificar se ocorrerão diferenças também no indivíduo adulto.

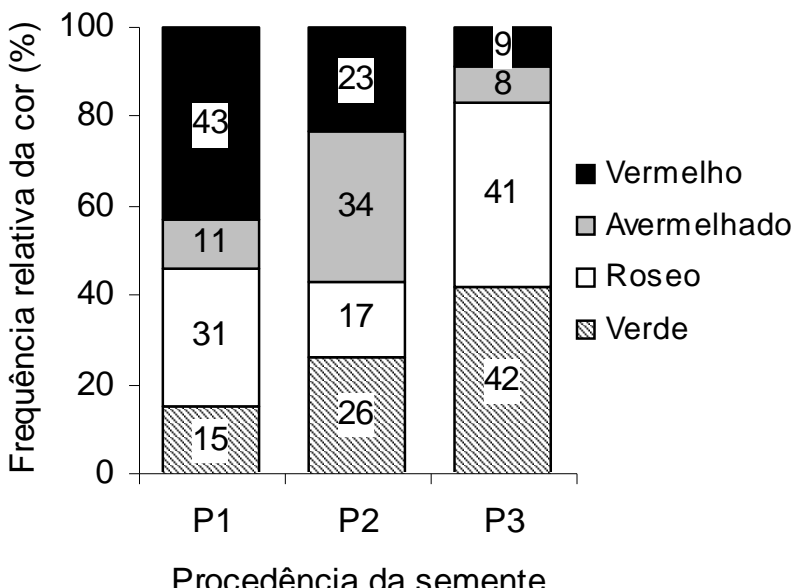

FIGURA 8. Freqüência relativa da coloração do caule das plântulas.

\section{CONCLUSÃO}

A procedência das sementes influencia nas características biométricas das sementes e no tempo médio de emergência e desenvolvimento das plântulas de Brosimum gaudichaudii. A porcentagem de emergência foi maior para sementes provenientes de $\mathrm{P} 1$ enquanto que as sementes provenientes de P3 formaram plântulas de maiores alturas.

\section{AGRADECIMENTO}

Os autores agradecem a Drạ Hélida B. N. Borges - SEMA/MT pelo auxilio na coleta dos frutos, ao Herbário Central da UFMT pela identificação da espécie e a CAPES pela concessão de bolsa de estudo ao primeiro autor.

\section{REFERÊNCIA}

ALMEIDA, S.P. et al. Cerrado: espécies vegetais úteis. Planaltina: Embrapa, 1998. 464p.

ALVES, E.U. et al. Influência do tamanho e da procedência de sementes de Mimosa caesalpiniifolia Benth sobre a germinação e vigor. Revista Árvore, v.29, n.6, p.877-85, 2005.

BRASIL. Ministério da Agricultura e Reforma Agrária. Regras para análise de sementes. Brasília: SNDA/ DNDV/CLAV, 1992. 365p.

BORGHETTI, F.; FERREIRA, A.G. Interpretação de resultados de germinação. In: BORGHETTI, F.; FERREIRA, A.G. (Orgs.) Germinação: do básico ao aplicado. Porto Alegre: Artmed, 2004. p.209-22.

BOTEZELLI, L.; DAVIDE, A.C.; MALAVASI, M.M. Características dos frutos e sementes de quatro procedências de Dipteryx alata Vogel (Baru). Cerne, v.6, n.1, p. 9-18, 2000.

CARVALHO, N.M.; NAKAGAWA, J. Sementes: ciência, tecnologia e produção. 4.ed. Jaboticabal: Funep, 2000, 588p.

FERNANDEZ, J.R.C. Efeito de substrato, recipiente e adubação na formação de mudas de mangabeira (Hancomia speciosa Gomes). 2002. 65p. Dissertação (Mestrado em Agricultura Tropical) - Faculdade de Agronomia e Medicina Veterinária, Universidade Federal de Mato Grosso, Cuiabá.

FERREIRA, M.G.R.; TORRES, S.B. Influência do tamanho das sementes na germinação e no vigor de plântulas de Acacia senegal (L.) de Willd. Revista Brasileira de Sementes, v.22, n.1, p.271-5, 2000.

HANLEY, M.E. et al. Seed size and seedling growth: differential response of Australian and British Fabaceae to nutrient limitation. New Phytologist, v.174, p.381-8, 2007.

KRZYZANOWSKI, F.C.; VIEIRA, R.D.; FRANÇANETO, J.B. Vigor de sementes: conceitos e testes. Londrina: ABRATES, 1999. 218p.

LORENZI, H. Árvores brasileiras: manual de identificação e cultivo de plantas arbóreas nativas do Brasil. 2.ed. Nova Odessa: Instituto Plantarum, 2002. v.2, 368p.

LORENZI, H.; MATOS, F.J.A. Plantas medicinais no Brasil: nativas e exóticas. Nova Odessa: Plantarum, 2002. 512p.

LABORIAU, L.G.; VALADARES, M.E.B. On the germination of seeds Calotropis procera (Ait) Ait.f. Anais da Academia Brasileira de Ciências, v.48, n.2, p.263-84, 1976.

LEONHARDT, C. et al. Maturação fisiológica de sementes de tarumã-de-espinho (Citharexylum montevidense (Spreng.) Moldenke-Verbenaceae), no Jardim Botânico de Porto Alegre, RS. Revista Brasileira de Sementes, v.23, n.1, p.100-7, 2001.

MALAVASI, U.C.; MALAVASI, M.M. Influência do tamanho e do peso da semente na germinação e no estabelecimento de espécies de diferentes estágios da sucessão vegetal. Floresta e Ambiente, v.8, n.1, p.211-5, 2001.

MARTINS, C.C. et al. Influência do peso das sementes de palmito-vermelho (Euterpe espiritosantensis Fernandes) na porcentagem e na velocidade de germinação. Revista Brasileira de Sementes, v.22, n.1, p.47-53, 2000. 
NIETSCHE, S. et al. Tamanho da semente e substratos na germinação e crescimento inicial de mudas de cagaiteira. Ciência e Agrotecnologia, v.28, n.6, p.13215, 2004.

PEREIRA, E.C.B. et al. Seedling growth of mamacadela (Brosimum gaudichaudii Trec.) on six different substrates. Revista Brasileira de Plantas Medicinais, v.8, p.190-2, 2006.

POPINIGIS, F. Fisiologia da semente. 2.ed. Brasília: ABRATES, 1985. 298p.

RATTER, J.A.; RIBEIRO, J.F. Biodiversity of the flora of the Cerrado. In: SIMPÓSIO SOBRE O CERRADO, 8.,1996, Brasília. Anais... Planaltina: Embrapa - CPAC, 1996. p.3-5. REY, P.J. et al. Seedling establishment in Olea europaea: seed size and microhabitat affect growth and survival. Ecoscience, v.11, n.3, p.310-20, 2004.
RIBEIRO, J.F.; WALTER, B.M.T. Fitofisionomias do bioma Cerrado. In: SANO, S.M.; ALMEIDA, S.P. (Eds.). Cerrado: ambiente e flora. Planaltina: Embrapa-CPAC, 1998. p.89166.

SCHEFFER, M.C.; MING, L.C.;ARAÚJO, A.J. Conservação de recursos genéticos de plantas medicinais. 1999. Disponível em: <http://www.cpatsa.embrapa.br/catalogo/ livrorg/medicinaisconservação.pdf>. Acesso em: 25 mai. 2006.

SILVA, A. et al. Influência do tamanho sobre a qualidade das sementes de Eucalyptus maculata Hook. Revista Brasileira de Sementes, v.16, n.2, p.187-90, 1994.

SOKAL, R.R.; ROHLF, F.J. Biometry: the principles and practice of statics in biological research. New York: Freeman \& Company, 1997. 887p. 